\title{
The decision-making process in nutritional surveillance in Europe
}

\author{
BY ANNA FERRO-LUZZI AND CATHERINE LECLERCQ \\ National Institute of Nutrition, Via Ardeatina, 546, 00178 Rome, Italy
}

Surveillance in general has been defined as the systematic collection and analysis of data pursued with well-defined objectives. More specifically, a Nutritional Surveillance System (NSS) scrutinizes the occurrence in a population of dietary-mediated nutritional conditions, with the objective of describing the current situation, detecting trends, forecasting changes, highlighting priorities and targeting corrective and preventive measures (World Health Organization, 1976; Eylenbosch \& Noah, 1988; Kelly, 1988; Mason et al. 1987).

\section{THE CONCEPTUAL FRAME}

The setting up of an NSS is a multi-stage process requiring a number of sequential steps. The first step consists of assessing the nature and the dimensions of the health problem of the country where the NSS is intended to operate. The next step is a priority setting exercise to be conducted on the double basis of the costs of the diseases and of the feasibility of their prevention. A working hypothesis of likely casual relationships for each of the priority areas makes it possible, as a fourth step, to select suitable indicators and establish appropriate cut-off points. Action-triggering levels may then be set, and medium- and long-term goals established. Finally an inventory of all existing datacollecting centres is made, in order to make maximum use of readily available indicators; finally the conditions are created for activating a regular and sustained flow of secondary information from the periphery to a data-processing central structure. Ad hoc surveys, generating new and necessary data, again on a regular basis and on nationally representative groups of population may need to be designed, planned and carried out.

\section{ASSESSING THE DIMENSIONS OF THE HEALTH PROBLEM}

The first step in an NSS consists in establishing the nature and the size of the nutrition-related health problems of the country where the system is intended to operate. In the European region vital statistics provide an excellent source of information for revealing the main public health problems. Mortality statistics are regularly collected by fairly standardized and codified procedures, and are readily available. On the other hand, much less data are available on morbidity; therefore, unless special surveys are conducted, prevalence and incidence of non-lethal, but possibly highly prevalent disorders, such as obesity, caries, iron-deficiency anaemia, osteoporosis, and goitre, may be assessed only with great difficulty.

Table 1 describes the ten major causes of death in selected European countries in recent years, altogether accounting for $76-88 \%$ of all deaths (World Health Organization, 1988). These data leave little doubt as to which are the most prominent health problems. Cardiovascular disease (CVD) is shown to be responsible for $27 \%$ of all deaths in Italy, about half these deaths being ascribed to ischaemic heart disease (IHD). 
Table 1. The ten major causes of death (\% total) in some European countries in recent years (World Health Organization, 1988)

\begin{tabular}{|c|c|c|c|c|c|c|}
\hline Cause of death & Italy & Portugal & France & Greece & UK & Germany \\
\hline $\begin{array}{l}\text { Heart disease } \\
\left(\text { CHD* }^{*}\right)\end{array}$ & $\begin{array}{c}27 \\
(46)\end{array}$ & $\begin{array}{c}17 \\
(52)\end{array}$ & $\begin{array}{l}22 \\
(46)\end{array}$ & $\begin{array}{c}30 \\
(36)\end{array}$ & $\begin{array}{l}32 \\
(85)\end{array}$ & $\begin{array}{c}34 \\
(59)\end{array}$ \\
\hline $\begin{array}{l}\text { Cancers } \\
\text { (Gastric, colon, breast }\end{array}$ & 24 & 18 & 24 & 20 & 25 & 24 \\
\hline and prostatet) & $(32)$ & (42) & (30) & (24) & (34) & (37) \\
\hline Cerebrovascular discase & 14 & 25 & 11 & 19 & 12 & 13 \\
\hline Violent dcaths & 5 & 7 & 9 & 5 & 3 & 5 \\
\hline $\begin{array}{l}\text { Chronic obstructive lung } \\
\text { disease }\end{array}$ & 4 & 2 & 2 & 1 & 2 & 3 \\
\hline Diabetes mellitus & 3 & 2 & 1 & 1 & 1 & 2 \\
\hline Liver cirrhosis & 3 & 3 & 2 & 1 & - & 2 \\
\hline Arteriosclerosis & 3 & 2 & - & - & 1 & 2 \\
\hline Pneumonia, influenza & 2 & 2 & 3 & 2 & 5 & 2 \\
\hline Embolism, thrombosis, etc. & 1 & - & 2 & 1 & 2 & 1 \\
\hline Total & 88 & 78 & 76 & 80 & 83 & 88 \\
\hline
\end{tabular}

CHD, coronary heart disease.

* As percent of heart disease.

$\div$ As percent of all cancers.

Cancers occupy the next place, accounting for nearly one in four deaths, with $32 \%$ of these due to gastric, colon, breast and prostate cancers. Stroke and cerebrovascular disease cause $14 \%$ of all deaths. Combined, these three conditions account for $65 \%$ of all deaths, i.e. more than 350000 deaths per year.

It can be noticed that the ranking order of the various causes of death differs between countries, with cerebrovascular disease acquiring the most prominent position in Portugal, whereas in the UK nearly one-third of deaths are caused by CVD, which are almost totally accounted for by IHD. Differences in the ranking orders exist also for other diseases and need to be taken into account when deciding priorities, especially at an international level.

\section{DIETARY RISK FACTORS: THE EVIDENCE}

In the context of nutritional surveillance, it is crucial to establish which of the killer diseases listed in Table 1 are dietary related. This area is still somewhat controversial, the matter being complicated by the large variety of factors involved, the long latency period between dietary exposure and expression of the chronic disease (Rose, 1982), and the intricate interplay between genetics, environment and behaviour. Despite these limitations, a fairly general and solid consensus currently exists on the general importance of diet in the pathogenesis of several of the chronic diseases listed in Table 1 as well as of other non-lethal or only indirectly lethal conditions. The list of all the medical conditions for which a dietary risk factor has been postulated is long and also differs somewhat among various sources. So, for example, coronary heart disease (CHD), stroke, hypertension and cerebrovascular disease, several cancers, diabetes mellitus, obesity, caries, and gallstones are listed in all the sources cited in Table 2 (Deutsche Gesellschaft für Ernahrung, 1988; James, 1988; US Department of Health \& Human Services, 1988; 
Table 2. Medical conditions listed in various reports as dietary-related

\begin{tabular}{|c|c|c|c|c|}
\hline & USA* & Germany ${ }^{\dagger}$ & Europe $\ddagger$ & World $\mid$ \\
\hline Coronary heart disease, cardiovascular disease & + & + & + & + \\
\hline Cerebrovascular disease, hypertension & + & + & + & + \\
\hline Cancers & + & + & + & + \\
\hline Non-insulin-dependent diabetes & + & + & + & \\
\hline Obesity & + & + & + & + \\
\hline Caries & + & + & + & + \\
\hline Gallstones, gall bladder disease & + & + & + & + \\
\hline Osteoporosis & + & + & & + \\
\hline Liver cirrhosis & + & + & + & \\
\hline Goitre, iodine-deficiency disorders & + & + & + & \\
\hline Iron-deficiency anaemia & & & + & + \\
\hline Osteomalacia & + & & + & \\
\hline Diverticulitis, -osis & + & + & & \\
\hline Protein-cnergy malnutrition & & & & + \\
\hline Vitamin A deficiency & & & & + \\
\hline Gout & & + & & \\
\hline Arthritis & & & + & \\
\hline Arteriosclerosis & & + & & \\
\hline Peridontal disease & + & & & \\
\hline Intestinal constipation & + & & & \\
\hline Pancreatitis & & + & & \\
\hline Infections and immunity & + & & & \\
\hline Rickets & + & & & \\
\hline
\end{tabular}

\footnotetext{
* US Department of Health \& Human Services (1988).

+ Deutsche Gesellschaft für Ernahrung (1988).

\pm World Health Organization (1988).

") World Health Organization (1990).
}

World Health Organization, 1990). The focus is fairly frequently also on osteoporosis and liver cirrhosis, and slightly less frequently on peripheral arterial diseases, gout, pancreatitis, arthritis, various gastrointestinal disorders (diverticulitis, constipation, etc.). Iodine-deficiency disorders and iron-deficiency anaemia are two nutrient deficiency conditions that feature prominently in developing countries, but may persist also in the European region.

The nature, strength and weakness of the evidence for a dietary factor in the aetiology of all these chronic diseases have been amply reviewed in recent years and have been the object of numerous publications and several consensus conferences (Burton et al. 1985; Reddy \& Cohen, 1986; Study Group of Atherosclerosis Society, 1987; Canadian Medical Association, 1988; US Department of Health \& Human Services, 1988; National Research Council, 1989; World Health Organization, 1990). They need not, therefore, to be reviewed again here.

\section{PRIORITY AREAS}

The next step involves the choice of areas for priority action. There are a number of criteria that govern this choice, the leading ones being the financial burden imposed by the dietary-related diseases on society, and the extent to which these diseases are avoidable. 
Table 3. Length of stay in hospital by cause and per admission, and total duration of hospital bed occupancy recorded in Italy in 1986

\begin{tabular}{lcc}
\hline Acute myocardial infarct & $\begin{array}{c}\text { Average duration of } \\
\text { hospitalization } \\
\text { (no. of d/admission) }\end{array}$ & $\begin{array}{c}\text { Total period of } \\
\text { hospitalization over 1 year } \\
\text { (no. of years) }\end{array}$ \\
Other coronary heart disease & $17 \cdot 2$ & 3216 \\
Hypertension & $13 \cdot 9$ & 6832 \\
Cerebrovascular disease & $13 \cdot 6$ & 5002 \\
Stomach cancer & $21 \cdot 6$ & 10795 \\
Colon cancer & $23 \cdot 4$ & 1673 \\
Breast cancer & $11 \cdot 9$ & 2781 \\
Diabetes & $15 \cdot 5$ & 694 \\
Liver cirrhosis and other chronic liver & $16 \cdot 6$ & 4795 \\
$\quad$ disease & $17 \cdot 1$ & 5903 \\
Gallstones & & 49167 \\
Total & \\
\hline
\end{tabular}

The cost of the diseases. Besides representing an important priority-setting element, direct and indirect costs of diseases have also a powerful advocacy value, policy makers being particularly attentive to this type of argument. Unhappily, health economists appear to find this area rather complicated, and are somewhat reluctant to engage in it. As a result, very few data of this nature are readily available, at least in Italy.

Direct costs are those associated with the management of medical disorders. They include hospitalization, out-patient clinics, domiciliary services, drugs and laboratory diagnostics, but may also include disability pensions and other expenses. These calculations involve a large amount of value judgements and approximations, present several conceptual problems, and are difficult to obtain. If detailed and complete direct costs data are not available, hospital bed occupancy can serve as a reasonable and convenient proxy. Table 3 provides an example; it shows the average length of stay in hospital for each admission and by cause, in Italy in 1986 (ISTAT, 1990a). The shortest duration is $11.9 \mathrm{~d}$ for breast cancer and the longest ones are those for colon and gastric cancers. In 1986, hospital beds were occupied for 15000 hospital years for heart diseases, another 11000 hospital years for cerebrovascular diseases, and 6500 hospital years for the specified cancers. A staggering grand total of 49000 hospital years is reached when adding up all the specified diseases. At an average cost of about $£ 200$ per $d(500000$ Italian lire; E. Gagliardini, personal communication), this translates to a total cost of about $£ 3.5$ billion per year.

Figures as large as these are by no means unusual. In the Netherlands the number of days of hospitalization for discases of the circulatory system has been calculated to amount to 4299 years in 1983 (Centraal Bureau voor de statistiek, 1986). Accounting for the smaller population of the Netherlands, this value is roughly comparable with the Italian one. At the estimated cost of a daily fee for hospital of 500 Dutch guilders, the total cost was calculated to be 785 million guilders, equivalent to about $£ 260$ million (Cholesterol Committee, 1990).

A somewhat similar calculation for the UK (Laing, 1981) revealed that the National Health Service was spending annually $£ 614$ million for the medical treatment of 
Table 4. Cost of some dietary-related diseases and potential annual saving of lives by dietary prevention in $U K$ in $1979-80^{*}$

\begin{tabular}{|c|c|c|c|c|}
\hline \multirow[b]{2}{*}{ Medical conditions } & \multirow[b]{2}{*}{ No. of deaths } & \multicolumn{2}{|c|}{ Savable life years } & \multirow{2}{*}{$\begin{array}{l}\text { Direct NHS } \\
\text { costs per year } \\
\text { (f millions) }\end{array}$} \\
\hline & & $<65$ years of age & $>65$ years of age & \\
\hline Constipation & 15 & 6 & 146 & 26 \\
\hline Intestinal diverticula & 1376 & 1450 & 12821 & 10 \\
\hline Diabetes mellitus & 3911 & 1125 & 39990 & 67 \\
\hline Alcohol and liver cirrhosis & 609 & 8303 & 7408 & 76 \\
\hline Obesity & 177 & 1222 & 2159 & 14 \\
\hline Colon cancer & 10346 & 26969 & 109217 & 28 \\
\hline Cholelithiasis & 524 & 765 & 4716 & 25 \\
\hline IHD & 77906 & 169960 & 752984 & 97 \\
\hline $\begin{array}{l}\text { Disease of the hard tissues of } \\
\text { the teeth }\end{array}$ & 0 & 0 & 0 & 271 \\
\hline Total & 94864 & 209530 & 929441 & 614 \\
\hline
\end{tabular}

IHD; Ischaemic Heart Disease: NHS, National Health Service.

* Modified from Laing (1981).

preventable dietary-related diseases (Table 4). This table also highlights the surprisingly high direct costs of a trivial condition as dental caries as compared with those of a lethal disease such as IHD. Similarly high direct costs for dental caries have been also reported for Germany, where they were said to absorb about one-fifth of the total direct costs of all diseases (Deutsche Gesellschaft für Ernahrung, 1988), and in the USA where they amounted to $6.5 \%$ of all national expenses for health in 1984 (US\$25 billion) and were projected to increase to US $\$ 42$ billion in 1990 (National Research Council, 1989).

Although these calculations need to be refined and must be used cautiously, it is obvious that figures of this magnitude represent a very convincing argument of enormous impact when setting priority areas for nutritional surveillance.

Direct costs are only one part of the total financial burden imposed on society by disease, and to really appreciate the totality of their impact, indirect costs, represented by the untimely loss of human capital, loss of opportunities and suffering, need also to be estimated. Unhappily, this calculation is even more arduous and imprecise than that of direct costs and raises many unresolved conceptual problems. Also in this case, however, it is legitimate to utilize more expedient but still reasonably meaningful proxies, such as the number of years of productive life lost (YPLL). These correspond to the difference between the age at death (years) and 65 years. So, for example, there were 132000 YPLL for CHD in Italy in 1987, 78000 for cerebrovascular diseases and 535000 for cancers (ISTAT, 1990b). By comparing the YPLL with mortality rates and hospital-bed occupancy, further elements for the decision-making process can be obtained. Fig. 1, for example, reveals that the diseases of the circulatory system are responsible in Italy for a proportion of premature mortality smaller than their impact on total morbidity and mortality (C. Leclercq and A. Ferro-Luzzi, unpublished results). The figure also indicates that while cancers represent a large proportion of all deaths, the diseases of the digestive system have higher direct costs, because of their longer hospitalization, than suggested by their impact on premature mortality rates. These discrepancies obviously 

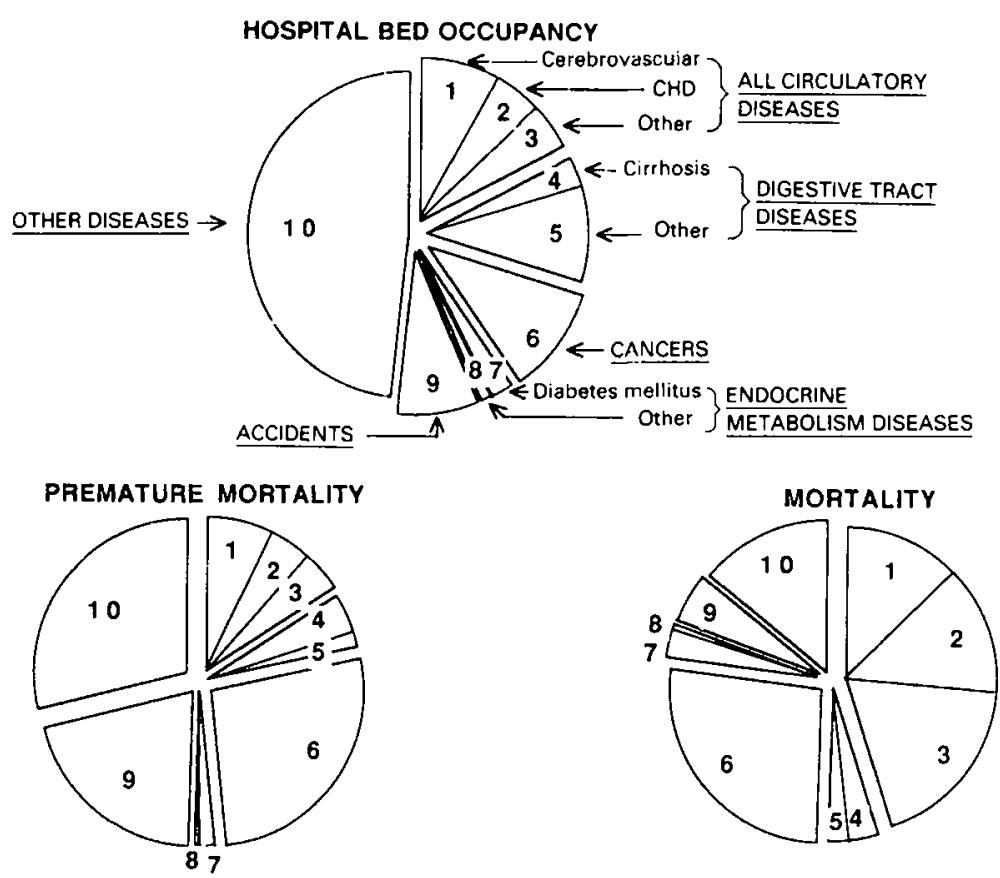

Fig. 1. The comparison of percentage contributions to total mortality rate, premature mortality (years of productive life lost (YPLL)); and hospital-bed occupancy (as proxy for medical costs of the management of the specified discase). The relative importance of a disease varies. depending on the criteria on which it is estimated. CHD, coronary heart disease.

reflect the different age-groups affected and the age at death for the various pathologies, but they also provide an approximation of the expected cost-effectiveness of preventive actions.

Preventability. The other important element of guidance for establishing priority areas in an action-oriented nutrition surveillance system is represented by the extent to which the prevalence of a disease can be reduced by changes in diet. The proportion of morbidity that can be avoided by dietary means varies considerably between diseases and can be only very roughly estimated either by extrapolating the results of intervention trials or by comparing contrasting populations. The estimate of the reduction of the prevalence of a disease is in fact the measure of a dose-response relationship and relies on the assumption that there is a causal relationship between a dietary variable and a measurable health disorder. The accuracy with which it can be calculated depends on the robustness. consistency, specificity, biological plausibility and temporal correctness of the evidence (National Research Council, 1989). In practice, however, the causality of the link between chronic conditions and diet is often inferred rather than demonstrated, and the preventability of the diseases remains rather difficult or impossible to quantify.

The case of CHD prevention is one of the most robust and least controversial. The integration of a vast body of scientific evidence accumulated through years of experimental, clinical and epidemiological research has firmly led to the conclusion that blood cholesterol is a powerful predictor of CHD (Keys, 1980). The relative CHD risk for blood cholesterol levels higher than $2560 \mathrm{mg} / \mathrm{l}$ has been calculated to be $1.5-3.6$ times 
that for blood cholesterol levels of $1940 \mathrm{mg} / \mathrm{l}$, for age-groups 60-64 and 45-50 years respectively (Pooling Project Research Group, 1978). The demonstration that dietary saturated fatty acids (SFA) are the major determinants of blood cholesterol concentration, explaining $60-80 \%$ of the interpopulation variance of blood cholesterol, dates back to the 1960s (Keys et al. 1965: Stallones, 1983). More precisely graded risks in cohort studies and the application of Keys' (1984) equation have made it possible to estimate that a $10 \%$ reduction in blood cholesterol (from about $2200 \mathrm{mg} / \mathrm{l}$ to $2000 \mathrm{mg} / \mathrm{l}$ ) produces a $20-30 \%$ decline in CHD deaths (National Research Council, 1989). Several intervention studies have confirmed this relationship, and the Oslo trial has shown that up to $60 \%$ of the decline in total mortality can be explained by dietary changes (Hjermann et al. 1981). An interesting ancillary point is that the prevention of CHD by dietary means appears to be remarkably more cost-effective than by cholesterol-lowering drugs (Kinesian \& Eisenberg, 1988; Cholesterol Committee, 1990).

Hypertension, a known risk factor for coronary heart disease as well as for stroke, provides another example of potentially successful dietary prevention. A recent metaanalysis of the data derived from several observational, cross-over and controlled trials on salt intake and salt reduction has confirmed that, at population level, a modest and easily achievable reduction in daily sodium intake by about $3 \mathrm{~g}$ salt, would induce a $5 \mathrm{~mm}$ $\mathrm{Hg}$ decrease in average systolic blood pressure (Law et al. 1991a,b). This decrease would translate to a $22 \%$ reduction in the incidence of stroke and a $16 \%$ decrease in the incidence of IHD. For a $6 \mathrm{~g}$ salt reduction, the impact in the UK would correspond to a reduction in stroke mortality by $39 \%$ and that for IHD by $30 \%$.

Dental caries represent another good example of preventability, as their incidence can be largely abated by reducing total intake of refined sugars and the frequency of their consumption (Newburn, 1982; Shaw, 1987). The protective effect of fluoridation has been shown to be less effective if sugars are consumed in large amounts and with a high frequency (Sheiham, 1983). Optimum results of fluoridation can be achieved only when average sugar is maintained below $15 \mathrm{~kg}$ /year (Sheiham, 1983). This corresponds to about $10 \%$ total dietary energy.

The last example is that of cancer. The potential impact of diet in terms of population-attributable cancer risks has been estimated by several authors, but always with a large margin of uncertainty and variability. Doll \& Peto (1981) have attempted to estimate the percentage of avoidable cancers and have come up with a range of values. between 10 and 70, distinguishing between the two sexes, with $30-40 \%$ of cancers attributable to diet for men, and about $60 \%$ for women. Other authors have calculated the potentially preventable proportion of various cancers as the difference in the incidence between two contrasting areas. The various approaches do not always give consistent estimates; however, it is fair to conclude that reasonable agreement exists for about $35 \%$ of cancers being avoidable on the basis of dietary modifications.

\section{CHOOSING THE: INDICATORS}

Having thus established, on the basis of prevalence, cost and preventability, which are the dietary-related medical problems that require priority attention in a nutrition surveillance system, the next step consists in formulating a working hypothesis of likely causal relationships for each priority area. This conceptual framework allows an 
Table 5. Categories of indicators for nutritional surveillance

\begin{tabular}{ll}
\hline Categories & Examples \\
Outcome indicators & Mortality statistics \\
& Morbidity statistics \\
Impact indicators & Other vital statistics. e.g. caries \\
& Blood pressure \\
& Blood cholesterol \\
& Body mass index \\
& Bone density \\
& Glucose tolerance, etc. \\
& Food \\
Exposure indicators & Nutrients \\
(or causal) & Non-nutrients \\
& Food-processing methods, ctc. \\
& Food prices \\
& Animal husbandry practices \\
& Consumer's knowledge and attitude \\
& Trends in food consumption, mortality, etc. \\
& \\
&
\end{tabular}

informed selection of suitable indicators on the basis of their measuring capacity, sensitivity and specificity. For action-oriented surveillance systems, indicators are then assigned trigger levels, which represent policy statements, specifying what proportion of sick persons in a society the system is willing to tolerate. Trigger levels are not absolute values, but depend on resources, cost-effectiveness considerations and political awareness.

For convenience indicators may be grouped into four broad categories (Table 5). The first category is the outcome indicators, and provides a measure of the end-points, either as terminal events such as the number of deaths for specific relevant causes, or as clinically assessed medical conditions, such as the incidence of non-mortal cardiac events or of hip fractures, or of caries.

The impact indicators are the second category. By supplying information on the prevalence in the population of biochemical, functional and anthropometric signs of health conditions or metabolic disorders, they provide a measure of the proportion of the population at risk of developing a disease after a given time-lag.

The causal indicators represent the dietary and nutrient correlates of the diseases and provide a measure of the exposure to a dietary risk factor. These indicators are mostly derived from food availability or food disappearance values, or from household budget surveys or more exceptionally from ad hoc food consumption surveys. They might ideally provide not only data on foods and nutrients, but also on non-nutrients present in the diet and on the ways foods are processed either at the industrial or domestic level.

The last category, represented by predictive indicators, groups together the environmental determinants of the exposure to dietary factors. Either as static, or even better as dynamic temporal series, these indicators can forecast health consequences of events occurring at various levels of the food chain, even if rather far removed from the consumer. 


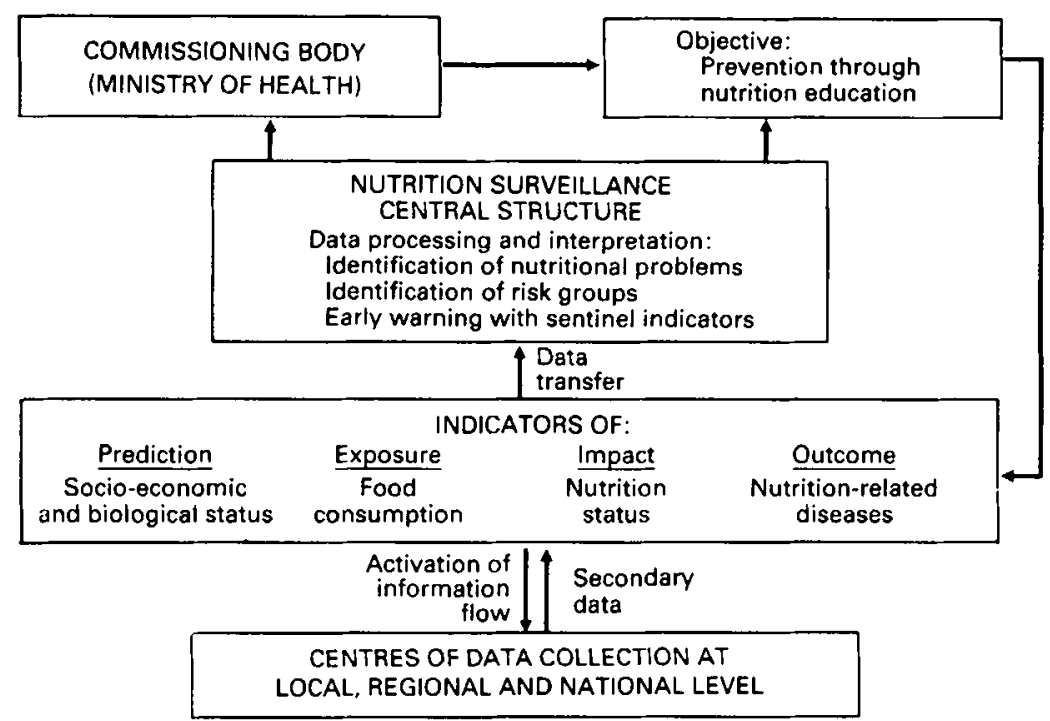

Fig. 2. Outline of the Italian Nutrition Surveillance System, based on secondary data.

\section{FROM THEORY TO PRACTICE}

Having thus described in its general line the conceptual process by which information is selected and indicators are developed for a nutrition surveillance system, what can be done in real life is dictated to a large extent by the actual conditions under which the system operates, the main constraints being the financia! resources available.

The data collection component represents by far the most expensive and difficult part of any surveillance system. It is not surprising, therefore, that in the European context, where NSS is not high amongst the priorities of governments, rather little systematic action is being undertaken in this area.

An example of a fairly well developed NSS is offered by the USA where the National Health and Nutrition Examination Surveys (NHANES) have reached their third generation, plus an Hispanic one (Olson, 1990). The USA are 20-40 years ahead of Europe in this field, and illustrate what can be achieved when political will and resources are not limiting factors. The system relies largely on ad hoc surveys and collects periodically vast amounts of primary data, biochemical, functional and dietary (McQuillan et al. 1990; Rizek \& Pao, 1990). This fairly well established and developed NSS is in the process of being even further strengthened as well as being set more firmly in a comprehensive and integrated plan of action by the forthcoming approval of the public law called the National Nutrition Monitoring and Related Research Act of 1990. The act disciplines the sustained collection of a vast number of data in several ad hoc surveys to be conducted in collaboration by the National Institute of Health and the US Department of Agriculture.

A contrasting example of a minimalist approach is that offered by Italy, where the Ministry of Health has recently appointed the National Institute of Nutrition to model a Nutrition Information System, specifying that it should make exclusive use of secondary data (Fig. 2). This minimalist approach has its own merits (can be run at almost no cost) 
Table 6. Example of inventory of centres collecting nutritionally relevant information in Italy, with comments relative to availability and quality of data

\begin{tabular}{|c|c|c|c|c|c|}
\hline \multirow[b]{2}{*}{ Information } & \multicolumn{5}{|c|}{ Centres } \\
\hline & $\begin{array}{c}\text { National } \\
\text { Institute } \\
\text { of Statistics* }\end{array}$ & $\begin{array}{l}\text { National } \\
\text { Health } \\
\text { Institute* }\end{array}$ & $\begin{array}{c}\text { Ministry } \\
\text { of Defence* }\end{array}$ & Hospitals $َ$ & $\begin{array}{l}\text { Universities } \\
\text { and Research } \\
\text { Institutes } \neq\end{array}$ \\
\hline Mortality & + & + & - & - & - \\
\hline \multicolumn{6}{|l|}{ Morbidity } \\
\hline National & + & + & - & - & - \\
\hline Select subgroups & + & + & - & + & + \\
\hline \multicolumn{6}{|l|}{ Dietary intakes } \\
\hline Food balance sheet & + & - & - & - & - \\
\hline Household budget & & & & & \\
\hline surveys & + & - & - & - & - \\
\hline Household surveys & - & - & - & - & + \\
\hline Individual surveys & & & & & \\
\hline national & + & - & - & - & - \\
\hline select subgroups & - & - & - & - & + \\
\hline BMI & + & - & + & - & + \\
\hline Blood components & - & - & - & + & + \\
\hline Caries & - & - & - & - & + \\
\hline Thyroid & - & - & - & - & + \\
\hline
\end{tabular}

BMI, body mass index.

* Nationally representative: periodically collected: easy access except for Defence Ministry; quality less than perfect

$\doteqdot$ Relevant to special subgroup: no or poor sampling; difficult retrieval.

$\ddagger$ Difficult access; representative of subgroups; point surveys.

and may give some good results, but clearly can only represent the intermediate and pilot stage. It is mentioned here because it requires a special course of action which might be neglected when NSS are designed de novo. This course of action puts a special emphasis on the creation of an inventory of all existing structures and centres that routinely collect at a national or local level relevant information (Table 6). Considerable effort must then be applied to assessing the quality of these data, the periodicity with which they are collected, the sampling frame, the level of aggregation, the format of data storage and their availability for the purpose.

The selection of indicators under this minimalist approach certainly requires a good degree of ingenuity because the choice is totally dominated by the nature of the available information and by the ability to create a nationally representative mosaic out of locally relevant and self-contained surveys.

Investigations need to be made to establish the opportunity and feasibility for improvement of the system at a relatively low cost by upgrading the quality, nature and amount of data routincly collected in these ongoing national or local surveys. These steps might absorb substantial effort, in proportion to the degrec of decentralization of the administration of the public health system, the smoothness and rapidity with which information can travel from the periphery to the centre and the ability of the central structure to receive and process the data. 


\section{CONCIUUSION}

There are no set rules about the format of an NSS, and a large variety of possible models can be thought of. However, a basic distinction can be made on the basis of the origin of the indicators used in the system: on the one hand, exclusive use of primary data specifically collected in ad hoc surveys, whilst on the other exclusive use of secondary data, generated for other purposes by other centres. Between these two extremes, there are all possible intermediate levels, the result representing the balance between resources available, political awareness and support, the nature and extent of other ongoing surveillance systems, and the nature and scverity of the dietary-related health problems. A judicious use of whatever secondary information is routinely available should always be pursued, and efforts directed to improve its quality.

Independent of the primary or secondary origin of the information utilized to develop the indicators, these are selected through a multi-stage priority-setting procedure, which starts by establishing country-specific priorities. Mortality statistics are useful for this, although changes in the morbidity:mortality ratios following improvements in the medical management of the condition or of its risk factors may complicate their interpretation. Non-lethal conditions, such as obesity, caries, goitres and anaemia almost invariably require ad hoc surveys, as mortality statistics do not apply and morbidity statistics are rarely available. Central to the priority-setting process should be the costs to society derived from dietary-related diseases and the extent to which they can be prevented.

The authors thank E. Toti and B. Rossi for technical assistance.

\section{REFERENCES}

Burton, B. T., Foster, W. R., Hirsch, J. \& Van Itallie, T. B. (1985). Health implications of obesity: an NIH Consensus Development Conference. International Journal of Obesity 9, 155-169.

Canadian Medical Association (1988). Canadian Consensus Conference on Cholesterol: Final Report. Ottawa: Canadian Medical Association.

Centraal Bureau voor de statistick (1986). Compendium Gezondheidsstatistiek 's-Gravenhage. The Netherlands: Centraal Bureau voor de statistiek.

Cholesterol Committee (1990). Report on Cholesterol. Health Council of The Netherlands Report no. 90/1. The Hague: Health Council of The Netherlands.

Deutsche Gesellschaft für Ernahrung (1988). Ernahrungshericht 1988. Frankfurt am Main: Deutsche Gesellschaft für Ernahrung E.V. (DGE).

Doll, R. \& Peto, R. (1981). The causes of cancer: quantitative estimates of avoidable risks of cancer in the United States today. Journal of National Cancer Institute 66, 1191-1308.

Eylenbosch, W. J. \& Noah, N. D. (editors) (1988). Surveillance in Health and Disease, pp. 9-24. Oxford: Oxford University Press.

Hjermann, I., Velve Byre. K., Holme, I. \& Leren, P. (1981). Effect of diet and smoking intervention on the incidence of coronary heart disease. Lancet ii, 1303-1310.

ISTAT (1990a). Statistiche della Sanità. Anno 1986. Annulario no. 2. Rome: ISTAT.

ISTAT (1990b). Cause di morte 1987. Annuario no. 3. Rome: ISTAT.

James, W. P. T. (1988). Healthy Nutrition. Preventing Nutrition-reluted Diseases in Europe. In collaboration with A. Ferro-I.uzzi, B. Isaksson and W. B. Szostak. WHO Regional Publications, European Series, no. 24. Geneva: WHO.

Kelly, A. (1988). Nutritional surveillance in Europe: an operational approach. In Surveillance in Healih and Disease, pp. 125-142 [W. J. Eylenbosch and N. D. Noah, editors]. Oxford: Oxford University Press.

Keys, A. (1980). Seven Countries: A Multivariate Analysis of Death and Coronary Heart Disease. London: Harvard University Press. 
Keys, A. (1984). Serum cholesterol response to dietary cholesterol. American Journal of Clinical Nutrition 40. 351-359.

Keys, A., Anderson, J. T. \& Grande, F. (1965). Serum cholesterol response to changes in the diet. IV Particular saturated fatty acids in the diet. Metabolism: Clinical and Experimental 14, 776-787.

Kinesian, B. P. \& Eisenberg, J. M. (1988). Cutting into cholesterol. Cost-effective alternatives for treating hypercholesterolemia. Journal of American Medical Association 259, 2249-2254.

Laing, W. A. (1981). The cost of diet-related diseases. In Preventive Nutrition and Society, pp. 55-76 [M. R. Turner, editor]. London: Academic Press.

Law, M. R., Frost, C. D. \& Wald, N. J. (199la). By how much does dietary salt reduction lower blood pressure? I-Analysis of observational data among populations. British Medical Journal 302, 811-815.

Law, M. R., Frost, C. D. \& Wald, N. J. (1991b). III-Analysis of data from trials of salt reduction. British Medical Journal 302, 819-824.

McQuillan, G. M., Gunter, E. W. \& Lannom, L. (1990). Field issues for the plan and operation of the laboratory component of the Third National Health and Nutrition Fxamination Survey. Journal of Nutrition 120, 1446-1450.

Mason, J. B., Habicht, J. P., Tabatabai, H. \& Valverde, V. (1987), La surveillance nutritionelle. Geneva: OMS.

National Research Council (1989). Diet and Health. Implications for Reducing Chronic Disease Risk. Washington, DC: National Academy Press.

Newburn, E. (1982). Sugar and dental caries: a review of human studies. Science 217, 418-423.

Olson, J. A. (editor) (1990). Nutrition monitoring and nutrition status assessment. Journal of Nutrition 120 , 1431-1549.

Pooling Project Research Group (1978). Relationship of blood pressure, serum cholesterol, smoking habit, relative weight and ECC abnormalities to incidence of major coronary events: final report of the Pooling Project. Journal of Chronic Diseases 31, 201-306.

Reddy. B. S. \& Cohen, L. A. (1986). Diet, Nutrition and Cancer: A Critical Evaluation, vols. 1 and 2. Boca Raton, Fl: C.RC Press, Inc.

Rizek, R. L. \& Pao, E. M. (1990). Dietary intake methodology. 1. USDA surveys and supporting research. Journal of Nutrition 120, 1525-1529.

Rose, G. (1982). Incubation period of coronary heart disease. British Medical Journal 284, 1600-1601.

Shaw, J. H. (1987). Causes and control of dental caries. New England Journal of Medicine 317, 996-1004.

Sheiham, A. (1983). Sugars and dental decay. Lancet i, 282-284.

Stallones, R. A. (1983). Ischemic heart disease and lipids in blood and diet. Annual Review of Nutrition 3, $155-185$.

Study Group of Atherosclerosis Society (1987). Strategies for the prevention of coronary heart disease: a policy statement of the European Atherosclerosis Society. European Heart Journal 8, 77-88.

US Department of Health \& Human Services (1988). The Surgeon General's report on nutrition and health. DHHS Public Health Service Publication no. 88-50210. Washington, DC: US Government Printing Office.

World Health Organization (1976). Methodology of Nutritional Surveillance. WHO Technical Report Series no. 593. Geneva: WHO.

World Health Organization (1988). World Health Statistics Annual. Geneva: WHO.

World Health Organization (1990). Diet, Nutrition and the Prevention of Chronic Diseases. WHO Technical Report Series no. 797. Geneva: WHO. 